\title{
Exploring Procedural Decision Support Systems for Wicked Problem Resolution
}

\author{
Carianne Pretorius \\ Department of Information Science, Stellenbosch University
}

\begin{abstract}
Wicked problems are hyper-complex problems that are not solvable via traditional methods. Some common examples of these include issues such as poverty, climate change, business strategy, and general policy development, which all have high stakes and no straightforward solution. The ambiguity of these problems can be particularly frustrating for the individuals and organizations that encounter them, as the very essence of these problems is elastic and unstable. Additionally, attempts to tame wicked problems tend to be irrevocable - for better or for worse - as the problem itself shifts in unpredictable ways in response. Decision support systems (DSSs) have long been considered a panacea for a number of highly complex problems in light of their potential to store, retrieve, and manipulate information to aid decision making. However, classical DSSs, being originally intended for semi-structured types of problems, are rendered practically impotent in the presence of wicked problems and their associated complexities. Thus, this article investigates the possibility of DSSs that rely on procedural rationality as an alternative strategy for resolving wicked problems. An empirical literature review is utilized to build and present an integrated, descriptive model for the design, development, and use of such DSSs for resolving wicked problems.
\end{abstract}

Keywords: decision support systems, decision making, wicked problems, procedural rationality

Categories: • Information systems $\sim$ Decision support systems $\bullet$ Social and professional topics $\sim$ Computing and business $\bullet$ Applied computing Enterprise computing

Email:

Carianne Pretorius C.Pretorius@tue.nl (CORRESPONDING)

Article history:

Received: 9 December 2016

Accepted: 18 April 2017

Available online: 9 July 2017

\section{INTRODUCTION}

\subsection{Background}

Traditional conceptualizations regarding the nature of human reasoning assume perfect rationality on the part of human decision makers (H. A. Simon, 1955, 1956). However, slightly more recent literature has made it plain that these classical assumptions are unrealistic. H. A. Simon (1955)'s bounded rationality shows us that humans possess limited knowledge about decision alternatives, and face serious limitations with regards to their computational ability and consistency of personal preferences. Further, H. A. Simon (1979) postulates the more realistic notion of heuristics, later

Pretorius, C. (2017). Exploring Procedural Decision Support Systems for Wicked Problem Resolution. South African Computer Journal 29(1), 191-219. https://doi.org/10.18489/sacj.v29i1.448

Copyright (C) the author(s); published under a Creative Commons NonCommercial 4.0 License (CC BY-NC 4.0).

SACJ is a publication of the South African Institute of Computer Scientists and Information Technologists. ISSN 1015-7999 (print) ISSN 2313-7835 (online). 
empirically confirmed by Tversky and Kahneman (1974), where humans implement 'rules of thumb' to arrive at a satisfactory rather than an optimal solution for a given decision problem. These heuristics, although not intrinsically problematic and despite their frequent ecological relevance ${ }^{1}$, have been shown to lead to serious errors in judgment in the face of complex decision making contexts (Tversky \& Kahneman, 1974), particularly since the decision maker's subjective perception of reality or frame has also been demonstrated to sometimes lead to further biases in heuristic selection (Tversky \& Kahneman, 1981). Thus, the normative requirements for rational decision making are consistently violated.

Decision support systems (DSSs) are information systems whose function is to improve the effectiveness and efficiency of a decision process (Arnott, 2006; Arnott \& Pervan, 2005; Keen \& Morton, 1978). These systems were developed originally to address large-scale planning problems (Power, 2002) in light of the abovementioned shortcomings of human rationality (Shim et al., 2002), but later found their niche in more semi-structured types of decision problems (Power, 2002; Sprague, 1980). Consequently, traditional DSS variants rarely offer appropriate solutions for particular breeds of unstructured problems that are ill-defined and wicked in nature (Mackenzie et al., 2006). Due to the nature of wicked problems in organizations, it is apparent that a different type of DSS is required in order to support these kinds of problems (Mackenzie et al., 2006). As Courtney asserts,

[o]rganizational decisions of the future may include social, environmental, and economical concerns, and be much more 'wicked', complex, and interconnected than those of the past. Organizations and their decision support systems must embrace procedures that can deal with this complexity and go beyond the technical orientation of previous DSSs. (2001, p. 17)

Authors such as Mackenzie et al. (2006) and Ritchey $(2011,2013)$ argue that this approach should be rooted in what is referred to as procedural rationality. H. A. Simon (1976) originally described this variant of rationality as referring to the appropriateness of the process of deliberation undertaken in a decision. The resulting procedural DSS is argued to provide better support for wicked problems (Mackenzie et al., 2006). A more complete version of this argument is presented in later sections of this article.

\subsection{Research Goals}

The objective of this study is to present the advantages of procedural decision support over substantive decision support, to explore the prevalence of each in the literature, as well as to present the nature of DSSs predicated on procedural rationality. This study therefore seeks to answer the questions outlined in Table 1.

The author would like to draw to the reader's attention the fact that this article extends a previous paper presented at the SAICSIT conference in September 2016 (Pretorius, 2016).

\footnotetext{
${ }^{1 ` E c o l o g i c a l ~ r e l e v a n c e ’ ~ r e f e r s ~ t o ~ t h e ~ r a t i o n a l i t y ~ o f ~ a ~ b e h a v i o r ~ b a s e d ~ o n ~ t h e ~ e n v i r o n m e n t a l ~ c o n t e x t . ~}$
} 
Table 1: Research question formulations

\begin{tabular}{|l|}
\hline Question \\
\hline $\begin{array}{l}\text { 1. What characteristics and activities facilitated by DSSs are desirable in } \\
\text { the context of wicked problems? }\end{array}$ \\
\hline $\begin{array}{l}\text { 2. What would a procedural DSS developed specifically for resolving wicked } \\
\text { problems look like? }\end{array}$ \\
\hline $\begin{array}{l}\text { 3. Which of procedural or substantive decision support approaches are } \\
\text { currently more prevalent for wicked problems in the literature? }\end{array}$ \\
\hline $\begin{array}{l}\text { 4. What is the level of cognizance of wicked problems in the context of } \\
\text { decision support in the literature? }\end{array}$ \\
\hline $\begin{array}{l}\text { 5. What types of wicked problems have been addressed using procedural } \\
\text { DSSs? }\end{array}$ \\
\hline
\end{tabular}

\subsection{Relevance for IS Research and Practice}

In order to effectively undertake research within the qualitative paradigm, context becomes imperative in producing a holistic overview of the domain under investigation (Babbie \& Mouton, 2007). Decision support systems are widely accepted in the literature as a category of information system and are classified as such. It therefore becomes pertinent to contextualize the DSS within the IS discipline, and to explore its relevance for research and practice within the IS field.

DSSs are primarily defined as a specific variant of IS whose purpose is to support and improve the decision making performance of managers or other information and knowledge workers (Arnott \& Pervan, 2005, 2008, 2014; Sprague, 1987). Here, the standard view of IS as per Avison and Fitzgerald (2002) is employed, that is, a computer-based system within an organization that provides information as well as processes that are useful to the organization in terms of helping said organization to operate more effectively.

Figure 1 outlines the context of DSSs within the scope of the IS field as per Burstein and Holsapple (2008). Here, DSSs as a category of IS types are subjected to similar forces of expansion to that of other information systems. From this model, it is clear that DSSs are affected by forces such as organizational computing, electronic commerce, and pervasive computing. Additionally, DSSs can be analyzed through the same lenses that are typically applied to ISs: conceptual, technical, analytic, economic, and behavioral approaches. Finally, the same six reference disciplines of IS research can be applied to DSS research and practice. Computer science, strategic management, organizational behavior, knowledge management, operations management, and quantitative methods are inextricably implicated in the growth of DSSs as a field, and are themselves impacted by this growth. Hence, modern decision support is fundamentally multidisciplinary in nature, and requires interaction with a wide range of approaches and theories (Burstein \& Holsapple, 2008). 


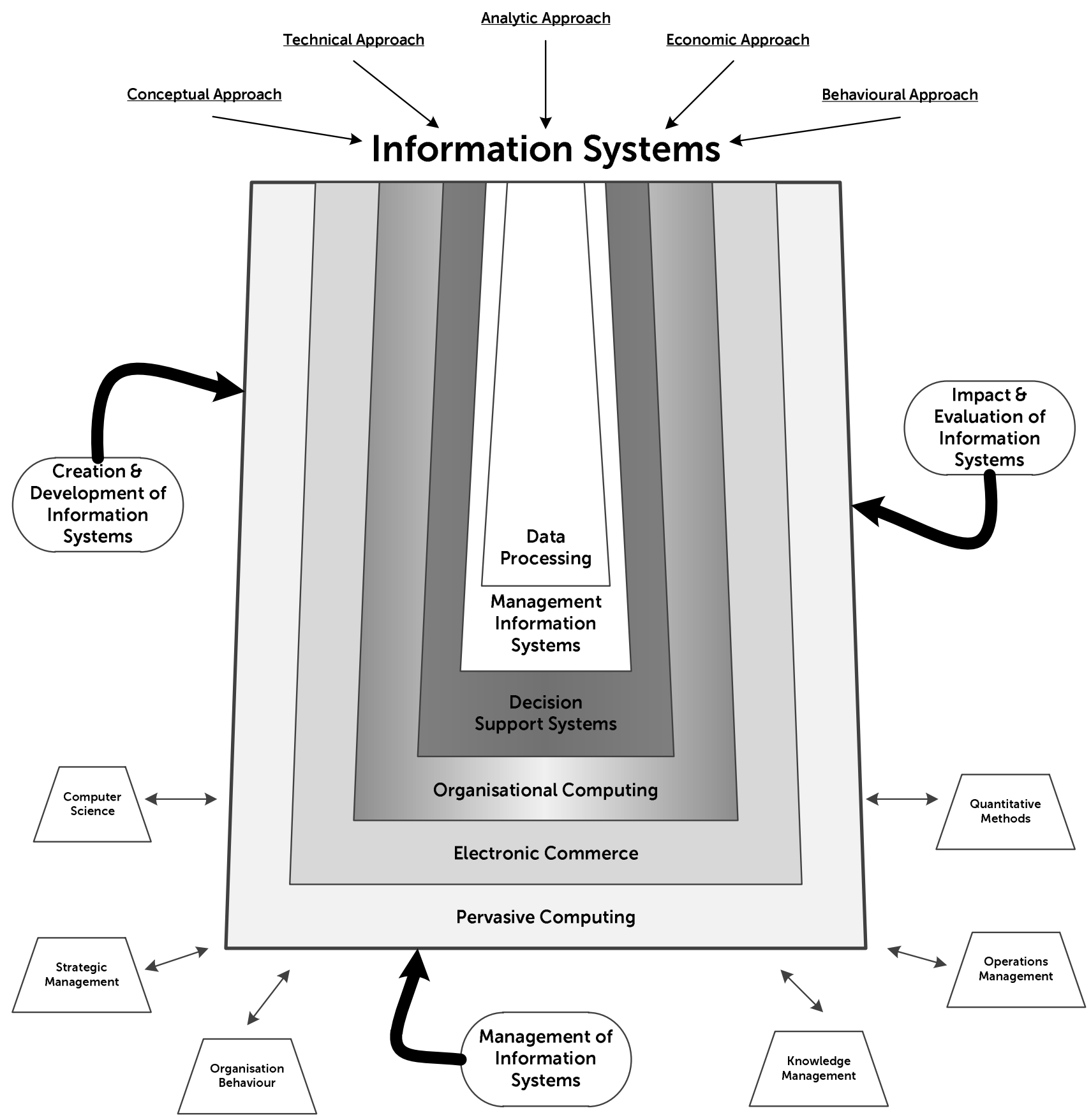

Figure 1: DSS and IS expansion as per (Burstein \& Holsapple, 2008) 


\section{THEORETICAL BACKGROUND}

Before delving into the study itself, important issues arising from the respective bodies of knowledge in the specific reference disciplines will be elucidated.

\subsection{Rationality and Decision Making}

\subsubsection{A Brief History}

Decision making as a field of inquiry is not a novel one. The concept, in its broadest form, has its roots in ancient Greek and Chinese epistemological and ontological inquiry (L. Buchanan \& O' Connell, 2006; Peterson, 2009), where philosophers such as Aristotle and Herodotus grappled with the notions of human preferences and rationality respectively (Carabelli, 2002; Hansson, 2002; Peterson, 2009). Later, during the Renaissance and Enlightenment eras, the study of probability, utility, and risk were added to the repertoire of study by mathematicians such as Bernoulli, de Fermat, and Pascal (Bernstein, 1996; Peterson, 2009). In the 1950s, mathematicians, economists, and cognitive psychologists began attempting to axiomize the principles behind the rational decision making process (Peterson, 2009). The field thus became more formalized as that which seeks to understand how humans make decisions under conditions of uncertainty (Hacking, 1972).

As with a number of other fields, decision making theories can operate at a descriptive or normative level. Here, normative theories endeavor to inform decision makers of how the process of reasoning, judgment, and decision making should occur, whereas descriptive theories seek to explain how people actually make decisions (Over, 2004). Decision making theories can thus describe the actual or the ideal, although some blurring between the boundaries has occurred over the course of the development of the field. However, it has been claimed by prominent decision making researchers such as Kahneman and Tversky (1979) that decision making theories are incapable of possessing both normative accuracy and descriptive veracity.

Much of the decision theory in the 20th century operated under an assumption that human decision makers acted in a manner that was perceived as rational (March, 1994). Here, rationality referred to the maximization of utility (Peterson, 2009) based on consistent preferences, and perfect knowledge of available options and their consequences (March, 1994). However, pure rational choice theory tends to break down under conditions involving any degree of uncertainty $(\mathrm{H}$. A. Simon, 1979). Expected utility theory (EUT) attempts to address this shortcoming by incorporating probabilities of outcomes into the decision making process, effectively weighting each choice in these terms (Friedman \& Savage, 1952; Mongin, 1997). Despite the fairly ubiquitous acceptance of EUT on a normative level, the theory has been challenged in terms of its descriptive validity, as assigning numerical values to constructs such as utility and probability has proven difficult (Friedman \& Savage, 1952; Kahneman \& Tversky, 1979; Mongin, 1997). Additionally, a number of alternative postulations and theories such as the Ellsberg paradox (Ellsberg, 1961), prospect theory (Kahneman \& Tversky, 1979), the Allais paradox (Allais, 1979), and the framing effect (Tversky \& Kahneman, 1981, 1986), have empirically shown how actual decision making processes consistently violate the axioms underpinning EUT. Therefore, the theory itself has largely been relegated to the realm of 
normative theories of decision making, with little to no appreciation as a descriptive theory.

In light of the obvious discrepancy between normative and descriptive value for theories of rational choice, the notion of bounded rationality was introduced by H. A. Simon (1955) in the 1950s. Rationality was still deemed relevant due to the assertion that human decision makers do intend to behave in a rational manner (March, 1994). However, this attempted rationality was asserted as that which "falls short of omniscience" (H. A. Simon, 1979, p. 502) due to a lack of knowledge of the various alternatives available, as well as various cognitive limitations that make calculating probabilities difficult (March, 1994). Therefore, rather than maximizing one's utility, the decision maker seeks to satisfice, terminating the search for alternative once a 'good enough' solution has been located (H. A. Simon, 1979).

Heuristics, as an extension of bounded rationality, are rules of thumb (Keren \& Teigen, 2004) that are cognitively simple, environment or context-specific, and focus on the process of problem solving as opposed to the outcome of the decision (Gigerenzer, 2004). Hence, Gigerenzer (2004) and Gigerenzer and Gaissmaier (2011) argue that the notion of heuristics is suitable both as a descriptive as well as a prescriptive theory, as these rules are empirically demonstrable and reduce the effort required for decision making through their ecological rationality. Tversky and Kahneman (1974), conversely, assert that these heuristics almost invariably lead to biases in judgment.

During this period, it became clear that descriptive theory was more concerned with exploring what decision making isn't as opposed to building actual positive models (Klein, 2008). Two major reactions to this fact began to emerge in the literature.

The first of these was the gathering of a small number of researchers at an invitation-only conference in 1989 in Ohio, USA, who were concerned with the applicability and validity of laboratory experiments for investigating decision making behavior in actual decision making contexts (Klein, 2015). And hence, the field of naturalistic decision making (NDM) was born, where read-world settings and pressures, decision makers with expertise in the problem domain, and the mental representation of the decision problem itself were noted as important themes (Lipshitz, Klein, Orasanu, \& Salas, 2001). All of these issues were argued to have profound relevance for decision making in real-life situations, where experience, uncertainty, and personal frames fundamentally matter for the decision context and cannot be controlled away.

The second reaction to this negative view of decision making arose through the application of dual-process theory as postulated by Evans (1984). Here, the notion of two systems of thought in the human mind was adopted by authors such as Stanovich and West (2000) to explain the gap between descriptive and normative accounts of decision making behavior. System 1 was described as the fast, associative, unconscious, and cognitively undemanding process, which was analagous to heuristic use, and system 2 was the slower, analytic, conscious, and cognitively demanding process. Kahneman (2011) extended this application by attributing the notion of system 1 to intuition, and system 2 to a type of applied reasoning process that has been labelled as the rationality process. Even though Kahneman (2011) does attribute much of the biases in reasoning from his early work with Tversky to errors produced by system 1 and inherited by system 2, he also emphasizes that both have their faults, and intelligent use of both is what ultimately leads to better decision making. Further, the notion of a decision being judged based on procedural rather than substantive rationality was 
presented by Kahneman (2011) as a possible driver for decision makers to make better decisions.

\subsubsection{Substantive and Procedural Rationality}

The comparison between the notions of substantive and procedural rationality was initially popularized by H. A. Simon (1976) in the context of economic theory (Pidd, 2004). This difference was highlighted primarily with the objective of demonstrating the descriptive validity of procedural rationality (H. A. Simon, 1976). Substantive rationality is behavior that is deemed appropriate given the decision maker's goal(s), while procedural rationality is that process of deliberation that is deemed appropriate given the decision (H. A. Simon, 1976). Therefore, substantive rationality refers to the substance of the decision, while procedural rationality refers to the process (Laville, 2000). Consequently, authors such as Mackenzie et al. (2006) and Pidd (2004) argue that procedural rationality is more suitable as an approach for supporting highly complex wicked problems.

\subsection{Wicked Problems}

Traditional scientific inquiry aims to address problems that have a definable essence and some associated discoverable solution. These tame problems, through their deterministic nature, lend themselves to measurement in terms of progress towards their goal, and eventual achievement of the goal itself (Rittel \& Webber, 1973). Wicked problems, in contrast, may be viewed as

[the] class of social system problems which are ill-formulated, where the information is confusing, where there are many clients and decision makers with conflicting values, and where the ramifications in the whole system are thoroughly confusing. (Churchman, 1967, p. B141)

Such problems are troublesome or impossible to define and therefore rely on human judgment for their resolution (Rittel \& Webber, 1973). They are never fully 'solved', but are continuously resolved as demanded by the context. The wicked descriptor indeed expresses the fundamentally mischievous or slippery nature of such problems, rather than an appeal to moral reprehensibility of some variety (Churchman, 1967). Some examples of wicked problems include water resource management (Freeman, 2000), resolution of health inequalities (Blackman et al., 2006), tackling global obesity (Swinburn et al., 2011), genetically modified food regulation (Durant \& Legge, 2006), recreation management (Brooks \& Champ, 2006), IT policy development (Korac-Kakabadse, Kouzmin, \& KoracKakabadse, 2000), environmental health promotion (Kreuter, De Rosa, Howze, \& Baldwin, 2004), fisheries and coastal governance (Jentoft \& Chuenpagdee, 2009), successfully addressing climate change (Lazarus, 2009), managing stakeholder networks (O’Toole, 1997), city planning (Skaburskis, 2008), information system design (R. Buchanan, 1992), public planning (Rittel \& Webber, 1973), and corporate strategy development and refinement (Camillus, 2008)

In spite of the intrinsic difficulty involved in defining a particular wicked problem's essence, there is an apparent consensus in the literature regarding various features or characteristics that may indicate that a problem is indeed wicked or possesses wicked elements (Camillus, 2008). In fact, two of the initial scholars in the field of wicked problems, Rittel and Webber (1973), developed a list 
of ten traits of wicked problems that may help decision makers and other stakeholders to recognize this so-called wickedness in a given problem. Rather than acting as absolute criteria or a checklist, these characteristics should be seen as more of an aid for appraisal of wicked elements of particular problem (Camillus, 2008). These traits are listed and compared with the contrasting features of tame problems as per Rittel and Webber (1973) in Table 2.

Table 2: Ten characteristics of wicked problems versus regular problems as per Rittel and Horst (Rittel \& Webber, 1973)

\begin{tabular}{|l|l|}
\hline Tame Problems & Wicked Problems \\
\hline Have a definite nature that can be sensibly formulated. & Very essence is in flux (Skaburskis, 2008). \\
\hline It is clear when a suitable solution has been found. & The termination point of solution search is unclear. \\
\hline There potentially exists a correct solution. & Solutions are measured by their relative goodness. \\
\hline $\begin{array}{l}\text { The outcome of an implemented solution can be evaluated } \\
\text { immediately and fairly accurately. }\end{array}$ & $\begin{array}{l}\text { The outcome of an implemented solution cannot be } \\
\text { evaluated immediately or ultimately. }\end{array}$ \\
\hline $\begin{array}{l}\text { Multiple attempts at a solution may be implemented } \\
\text { without significant cost. }\end{array}$ & $\begin{array}{l}\text { Solutions are one-shot operations; there is no opportun- } \\
\text { ity to learn via trial and error. }\end{array}$ \\
\hline Are usually governed by a finite set of rules. & Courses of actions do not exist as definitive sets. \\
\hline Rules exist for classifying collections of tame problems. & $\begin{array}{l}\text { Unique; experience isn't necessarily relevant (Camillus, } \\
\text { 2008). }\end{array}$ \\
\hline $\begin{array}{l}\text { Potentially has a natural level at which it can be addressed } \\
\text { in its own context. }\end{array}$ & $\begin{array}{l}\text { May be viewed as merely symptomatic of another, } \\
\text { greater problem. }\end{array}$ \\
\hline $\begin{array}{l}\text { The root of the problem exists objectively; plausible ex- } \\
\text { planations can be presented and refuted. }\end{array}$ & $\begin{array}{l}\text { The root of a wicked problem may be explained in a } \\
\text { number of equally acceptable ways. }\end{array}$ \\
\hline $\begin{array}{l}\text { Solutions to these problems are only hypotheses offered } \\
\text { in order for be refuted, and are not morally charged. }\end{array}$ & $\begin{array}{l}\text { Any implemented course of action may have moral con- } \\
\text { sequences for the decision maker. }\end{array}$ \\
\hline
\end{tabular}

In light of the resulting volatility, uncertainty of goals, as well as the cognitive deficiencies elucidated in the previous sections, it becomes clear that an alternative approach to decision making in wicked contexts is required (Laville, 2000). It is argued, as per Mackenzie et al. (2006) and Ritchey $(2011,2013)$ that this approach should be procedurally rational in nature.

\subsection{Decision Support Systems}

Particularly in the early literature, there appear to exist a number of identity crises experienced by the DSS field in the 1980s during its emergence (Pearson \& Shim, 1995). Firstly, there existed the contrasting views that DSSs as a construct emerged merely as an extension of management information system (MIS) research rather than an independent research area (Sprague, 1980), or as a radical reaction to MISs and their flaws (Arnott, 2006). Secondly, uncertainty was present regarding the normative scope of the DSS in the decision making process overall (Sprague, 1980), consequently leading to DSSs being used as an overarching term for any application that addressed decision making in some sense (Hayen, 2006). Thirdly and finally, the ever-changing nature of information technology and the resulting information systems necessarily implies that DSS application will also mimic this state of constant flux (Hayen, 2006). As a result, the definition of what constitutes a 
DSS can be difficult to reach consensus on in theory as well as in practice. Accordingly, a working definition is offered for the sake of consistency.

For the purposes of this article, a DSS is defined as some computer or IT-based (Arnott \& Pervan, 2008; Hayen, 2006; Keen \& Morton, 1978; Power, 2001; Shim et al., 2002) information system (Arnott \& Pervan, 2005; Arnott, 2006; Arnott \& Pervan, 2008; Power, 2001) that fulfills the purposes of supporting one or more stages of the semi-structured or unstructured decision making process (Keen \& Morton, 1978; Power, 2001; Sprague, 1980) rather than replacing decision maker judgment (Hayen, 2006). The primary aim of this system is to increase the effectiveness of this process rather than operational efficiency, though efficiency may exist as a secondary goal (Arnott \& Pervan, 2005; Arnott, 2006; Arnott \& Pervan, 2008; Hayen, 2006; Keen \& Morton, 1978; Pearson \& Shim, 1995).

A number of refinements to and adaptations of the definition have been made in response to changing organizational and technological landscapes over the years. Consequently, a variety of taxonomies and frameworks have been made by an assortment of authors. Factors considered include that of historical development and DSS types (Arnott \& Pervan, 2005, 2014; Power, 2008), the nature of the decision problem supported (Anthony, 1965; Gorry \& Morton, 1989; Hackathorn \& Keen, 1981; Mackenzie et al., 2006; H. Simon, 1960), the level of influence the system has on the final decision (Alter, 1977), design approaches (Keen, 1980), the type of specialized function each unit of the DSS performs (Bonczek, Holsapple, \& Whinston, 1981; Holsapple, 2008), and even an integration of all or a number of these facets (Sprague, 1980).

\subsubsection{DSS Architecture}

Holsapple (2008) defines a framework for DSSs in terms of the types of specialized functions each component of the system performs, which is based on a framework originally developed by Bonczek et al. (1981). The various components are:

- Language system (LS) - comprises all of the commands that the user is permitted to use to communicate with the DSS.

- Presentation system (PS) - involves all of the messages that the DSS can emit to its users. that the decision maker is permitted to use within the DSS.

- Knowledge system (KS) - contains the extent of stored knowledge in the problem domain. The knowledge is organized so as to enable and support retrieval thereof.

- Problem processing system (PPS) - this system acts as a software engine that attempts to recognize problems and derive solutions for them.

The user or users, whether they are a direct decision maker or some other stakeholder, generates a request in the form of a particular element of the LS. The PPS then processes that LS element, which may require some interaction with the KS contents or generation of new knowledge from an external source. The knowledge stored in the KS can therefore change in response to the processing tasks. The PPS may then emit a response to the user by exploiting one or more of the available PS elements presented to the user. 
Table 3: DSS types as per Arnott and Pervan (2014)

\begin{tabular}{|l|l|}
\hline DSS Type & Description \\
\hline $\begin{array}{l}\text { Personal decision support system } \\
\text { (PDSS) }\end{array}$ & $\begin{array}{l}\text { Smaller scale systems that are developed for one or a small group } \\
\text { of managers, generally to support a single decision process. }\end{array}$ \\
\hline Business intelligence (BI) & $\begin{array}{l}\text { Larger systems, often based on a data warehouse or other forms } \\
\text { of big data, that display data and analytics in a manner to support } \\
\text { decision making at multiple management levels. }\end{array}$ \\
\hline Group support systems (GSS) & $\begin{array}{l}\text { Combination of DSS and communication tools to facilitate group } \\
\text { decision processes. }\end{array}$ \\
\hline Negotiation support systems (NSS) & $\begin{array}{l}\text { Similar to GSS, but primary focus of group work is negotiation } \\
\text { between conflicting groups. }\end{array}$ \\
\hline Intelligent DSS (IDSS) & DSS that makes use of artificial intelligence (AI) techniques. \\
\hline $\begin{array}{l}\text { Knowledge management-based DSS } \\
\text { (KMDSS) }\end{array}$ & $\begin{array}{l}\text { Decision support is enabled through knowledge management tech- } \\
\text { niques: knowledge storage, retrieval, transfer, and application. } \\
\text { Supports organizational memory. }\end{array}$ \\
\hline
\end{tabular}

\subsubsection{DSS Types}

A large number of DSS taxonomies exist in the literature, due to varying vantage points as well as the relationship between DSS development and the advancement of information technology. Probably the most widely-accepted account in recent literature is that of Arnott and Pervan (2014), which was published in 2014. The various types of DSSs along with their descriptions are outlined in Table 3.

Each of the addressed categories has some historical significance in accordance with developments at the time. A notable example of this is the advent of the world wide web and the big data movement, which has increased interconnectivity and the necessary scale of DSSs (Arnott \& Pervan, 2014; Power, 2008).

\subsubsection{Procedural DSSs}

The differentiation between substantive and procedural rationality discussed earlier in this section leads to the possibility for DSS classification in terms of the complexity of the decision or problem situation that the system aims to support (Mackenzie et al., 2006). Substantive DSSs attempt to support decision makers through the provision of knowledge-based expertise as per the traditional architecture discussed above. It is argued that these DSSs are suitable for solving the aforementioned tame types of problems that require knowledge provision and computational support, but are ill-suited for wicked problems (Mackenzie et al., 2006; Ritchey, 2011, 2013). A common mistake made by individuals and organizations involves the attempt to tame the wicked problem through structuring it in a manner that makes the problem appear easier to solve (Conklin, 2005). Unfortunately, this strategy only serves to deceive stakeholders regarding the nature of the problem (Churchman, 1967; Rittel \& Webber, 1973), and often causes the problem to either reassert itself or exacerbate the very wickedness that taming sought to erase (Conklin, 2005; Roberts, 2000).

In contrast to taming a wicked problem, procedural DSSs provide a number of processes and tools 
to support decision makers during the actual process of making a decision by facilitating alternative search, analysis of alternatives, conflict resolution, and transparency of deliberations to stakeholders involved in the problem (Mackenzie et al., 2006). Procedural DSSs allows for exploration of the wicked problem by facilitating navigation of the decision space in all of its complexity (Mackenzie et al., 2006). This supports a life cycle approach where decision makers can interact with the problem as it changes, measure progress, document actions and strategies, and allow for discussion and debate amongst stakeholders (Ritchey, 2011, 2013), which are necessary for successful engagement with a wicked problem (Brooks \& Champ, 2006; Camillus, 2008; Conklin, 2005; Kreuter et al., 2004; Kunz \& Rittel, 1970; Roberts, 2000).

As an example, Mackenzie et al. (2006) developed a process and accompanying decision support tool called Wisdom for the express purpose of tackling wicked problems in a procedurally rational way. They asserted that in developing a procedural DSS, the overall goal was to create a tool to "support people in addressing the why and what questions, rather than just helping them to think about how an objective should be achieved" (Mackenzie et al., 2006, p. 158). Specifically, the authors aimed their process and DSS at strategic decisions, which they argue to be wicked due to future uncertainty and variability of perspectives through the presence of multiple stakeholders in strategy formation. The process itself is run in the following manner. Firstly, at least one faciliator and numerous other stakeholders participate in a brainstorming process, where participants provide nodes that are added to a visual map. This process can be achieved with the facilitator first capturing all nodes, and followed by participants interacting with the map through their web browser. These cognitive maps are then increasingly refined to build a more formalized dialogue map based on questions that the facilitator provides. These maps can be stored for future reuse and reflection. The authors also provided a case study involving a defense technology organization's strategy development workshop, where the authors and associated stakeholders noted that the tool contributed to the success of the workshop, as the goals of faithfully representing the problem space and developing a shared mental picture were achieved.

\section{RESEARCH DESIGN}

Previously, it was argued that wicked problems require a novel approach to decision support that differs from that of semi-structured or structured problems. Although literature regarding wicked problems and procedural DSSs is readily available, there is a distinct lack of a comprehensive literature review studying the role of procedural DSS in addressing wicked problems. To this end, the aim of this article is to address the research questions outlined in the first section by means of a holistic, integrated, and systematic literature study. The details regarding the design and methodologies employed in this study will be discussed in this section.

\subsection{Literature Search and Review Strategy}

The strategy implemented for search and review was completed in a number of cycles. For each iteration of the process, a keyword search was employed to locate a number of initial sources. Each 


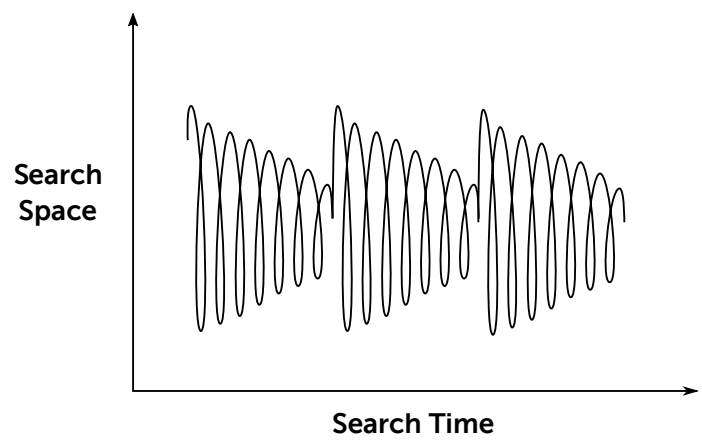

Figure 2: Metaphorical concertina structure of literature search as per (Levy \& Ellis, 2006)

of these was scanned for relevance to the study, and were either retained or discarded. A snowball sampling approach was utilized to discover additional related sources from the bibliographies of relevant studies. Each of these iterations led to the discovery of additional keyword combinations that were implemented in the following cycle of keyword searching and associated snowball sampling. The manner in which this was approached is metaphorically similar to a concertina, an analogy postulated by Levy and Ellis (2006), with cycles of gradual narrowing and subsequent enlargement of the search space. This process is demonstrated in Figure 2.

\subsubsection{Initial Keyword Search}

In conducting the keyword searches, a number of keyword combinations were employed. These included the term 'decision support system' or 'decision support' combined with the terms 'wicked problem', 'unstructured problem', 'ill-structured problem', and 'complex problem' respectively. The rationale behind these pairs of search terms and the use of the AND operator was to attempt to locate studies that mentioned DSSs or decision support generically, and also considered issues around wicked, unstructured, ill-structured, or complex problems.

The keyword searches were carried out in the EBSCOhost (EBSCO Industries Inc, 2015) and Web of Science (Thomson Reuters, 2015) databases through the university's library service pages. These particular databases were selected for the initial literature search due to their wide scope in the sciences, as well as the options available for further refining search results. Due to the interdisciplinary nature of the information systems field in general, as well as the application areas of DSSs, it was also considered important to consider journals that appear to exist outside of the fields of direct interest (Webster \& Watson, 2002). This ensured that studies implementing DSSs in applied wicked problem contexts were also located. In line with the literature selection strategy outlined by Levy and Ellis (2006), only peer-reviewed journal articles were included in the database searches. This means that professional magazines and conference proceedings were not included in the search; not due to quality concerns, but due to the need for a homogenous set of studies. 


\subsubsection{Snowball Sampling}

Following the collection of an initial set of quality literature, additional strategies were utilized to gather additional research. These entailed systematic methods initially suggested by Webster and Watson (2002) for information systems research, and reiterated by Levy and Ellis (2006) along with further suggestions. Backward search involved studying bibliographies of collected studies to locate works that seemed relevant, as well as further search via prominent author names that emerged. Forward search involved the location of studies that cited a particular collected source via citation counter links.

\subsubsection{Literature Selection}

Following a number of cycle iterations, it became clear that fewer and fewer citations were emerging, signaling the completion of the literature search within its scope as recommended by Levy and Ellis (2006) as well as Webster and Watson (2002). The next phase of the literature review involved the selection of relevant sources from the gathered literature.

The initial sample of collected literature consisted of $n=104$ peer-reviewed journal articles that matched the criteria specified in the search strategy. In order to refine the sample, each source was analyzed in terms of the actual content and topics considered to ensure that the article directly addressed some aspect of a problem deemed wicked in nature, and that an IT-based DSS was built, utilized, or recommended either conceptually or empirically. Due to these narrow requirements, a large quantity of the collected literature was discarded, resulting in a final sample of $n=35$ peer-reviewed articles from major journals in the information systems and DSS literature, as well as a number of applied fields.

\section{FINDINGS}

This section addresses the findings of the literature study through the lenses of quantitative and qualitative analysis respectively.

\subsection{Quantitative Analysis}

\subsubsection{Wicked Problem Categories}

Question 5 aims to discover the types of wicked problems addressed in the literature sample. To this end, the studies were coded in terms of a number of categories of wicked problem that were identified in the literature. Figure 3 displays each of these categories and associated frequencies. Accordingly, the most commonly addressed wicked problems in the context of DSSs in the literature sample are business, organizational and strategic decisions. This is fairly unsurprising due to the initial rise of awareness of wicked problems in the 1970s consisted primarily of organizational planning issues (Rittel \& Webber, 1973). Other categories of planning activities, such as environmental and natural resource planning as well as spatial planning, also appeared frequently. 


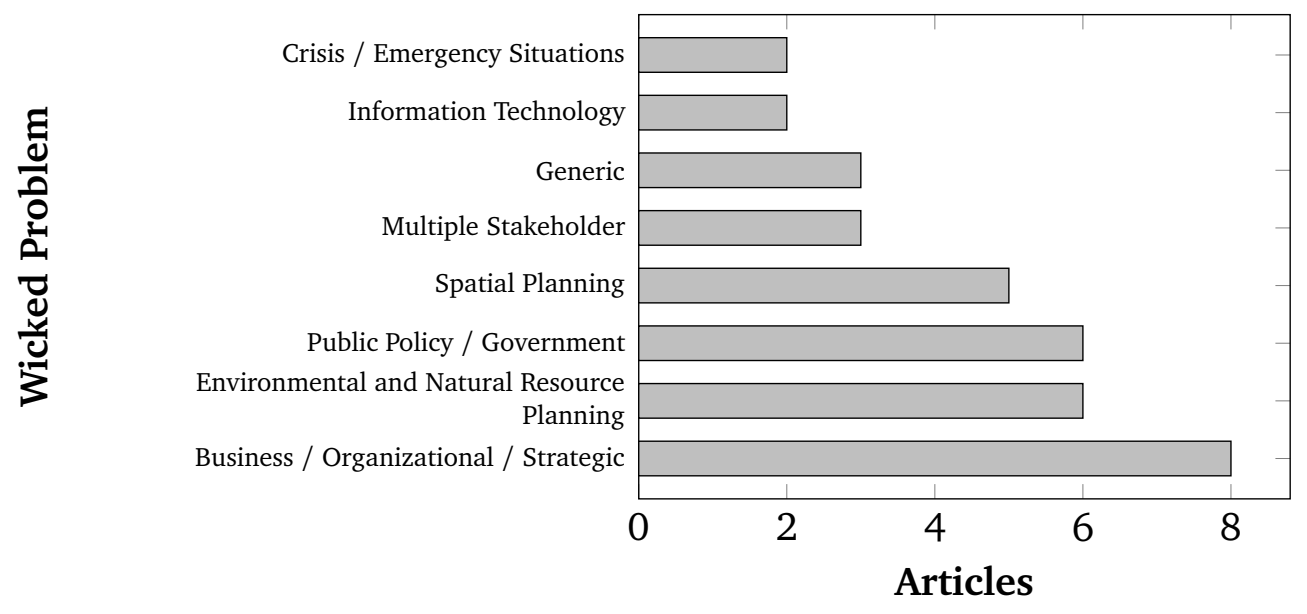

Figure 3: Distribution of wicked problem types in the literature

\subsubsection{DSSs for Wickedness}

The fourth question seeks to explore the cognizance of wicked problems in the context of DSSs over the lifespan of the literature. The findings are summarized in Figure 4 in relation to each five-year period.

Literature related specifically to DSSs for wicked problems only became prominent in the early 1980s following the emergence of research on conceptual issues regarding wicked problems, such those outlined by Kunz and Rittel (1970) as well as Rittel and Webber (1973). There are two clear outliers in the presented bar chart. The first refers to the time period of 1991 to 1995, where no articles were located that matched the aforementioned search criteria. The second outlier pertains to an increase to seventeen articles that were published between 2006 and 2010. Beyond these two exceptions, the published literature for each period is fairly consistent, with the trend demonstrating a gradual start, slight dip, and sudden peak late during the first decade of the 2000s. The author would like to bring the reader's attention to the fact that the literature sampling process was conducted during the latter half of 2015, meaning that the last sample may be somewhat incomplete due to the publishing cycle.

Table 4: Conceptions of rationality in literature

\begin{tabular}{|l|l|r|}
\hline Conception of Rationality & No. of Articles & \% \\
\hline Procedural & 23 & 65.7 \\
Substantive & 4 & 11.4 \\
Mixed & 5 & 14.3 \\
Not Applicable & 3 & 8.6 \\
\hline
\end{tabular}

\subsubsection{Substantive and Procedural Support}

The final question that will be answered using quantitative methods is that of Question 3, which asks which of procedural or substantive decision support approaches are currently more prevalent in the 


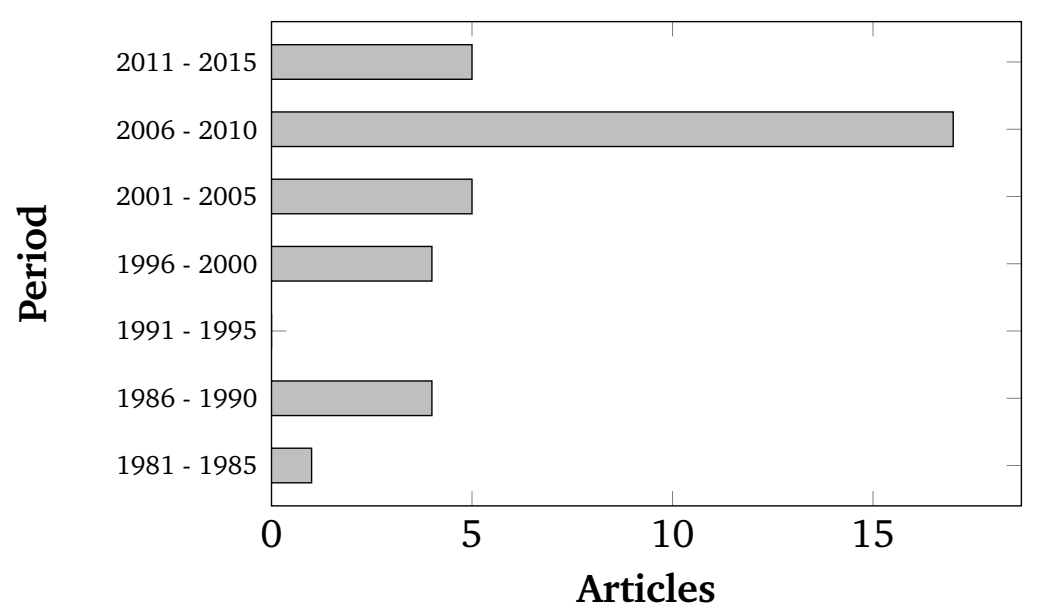

Figure 4: Number of articles on DSSs for wicked problems per period

literature. In order to analyze the literature, substantive decision support was viewed as focusing on goals; containing a knowledge base of options, algorithms, and calculations; and that algorithms aimed to derive the most preferable solution (Mackenzie et al., 2006). Conversely, procedural decision support was framed as focusing on processes; containing tools and processes to facilitate alternative search, information gathering, analysis, and conflict resolution; providing a framework to explore or navigate a given decision problem space; and relying on the reason and judgment of the decision maker themselves to 'find a way' through the decision situation (Mackenzie et al., 2006).

These categories were implemented as lenses that allowed for classification of each study. Heuristically, it was found that studies using some means of calculating an optimal solution were typically classified as implementing substantive decision support, whereas research that accentuated the deliberation process directly were generally classified as implementing procedural rationality. These findings are summarized in Table 4.

It is clear from the collected literature sample that procedural decisions support is by far the most common strategy employed for DSSs addressing wicked problems, comprising almost two thirds of the total number of articles (65.7\%). On its own, substantive decision support is the most rarely utilized form of decision support for these DSSs at just over one tenth of the literature (11.4\%). A slightly larger portion of the studies gathered (14.3\%) utilize both strategies in DSS conceptualization, design, or development, offering procedural methods to generate a greater number of alternatives and encourage stakeholder participation and collaboration, while later employing mathematical models to reach a solution.

\subsection{Qualitative Analysis}

Qualitative methods were employed for the remainder of the questions synthesized in the first section of the article; these inquire about subjects that are more complex in nature and require interpretation. 


\subsubsection{DSS Features for Wicked Problems}

In order to design, develop, and implement a quality information system, it becomes a necessary task to determine what is required of the system either in a linear fashion or through the process of a number of iterations (Avison \& Fitzgerald, 2002). Question 1 seeks to discover such requirements for DSSs for wicked problems in general. A number of these requirements were discovered in the literature sample:

- Participation and collaboration - most commonly cited requirement; stresses the importance of supporting collaborative understanding of the wicked problem situation. Examples include discussion facilitation, articulating preferences, enrichment of collective knowledge, and negotiating the strategy to be selected via consensus. Subjective perspectives and assumptions are emphasized (Balram \& Dragicevic, 2006; Cil, Alpturk, \& Yazgan, 2005; Conklin \& Begeman, 1989; Giordano, Passarella, Uricchio, \& Vurro, 2007; Gu \& Tang, 2005; Jankowski, Nyerges, Smith, Moore, \& Horvath, 1997; Jarupathirun \& Zahedi, 2007; Jarvenpaa, Rao, \& Huber, 1988; Karacapilidis, 2000; Karacapilidis \& Papadias, 2001; Klashner \& Sabet, 2007; Lourenço \& Costa, 2007; Mackenzie et al., 2006; McIntosh et al., 2011; Munneke, Andriessen, Kanselaar, \& Kirschner, 2007; Renton \& Macintosh, 2007; Ritchey, 2006; Van Kouwen, Dieperink, Schot, \& Wassen, 2009).

- Conflict management - the uncovered subjective nature and effects of wicked problems almost invariably leads to conflict. The literature postulates that rather than ignoring these conflicting views, they should be explored and reasoned through in a space that is considered safe for all stakeholders (El-Gayar \& Fritz, 2010; Giordano et al., 2007; Jankowski et al., 1997; Jarupathirun \& Zahedi, 2007; Karacapilidis, 2000; Karacapilidis \& Papadias, 2001).

- Scenario exploration and situation analysis - analyzing the problem situation in order to attempt refinement and further conceptualization of plausible alternatives and associated goals (Biermann, 2011; Giordano et al., 2007; Goslar, 1986; Jankowski et al., 1997; Marashi \& Davis, 2007; Van Kouwen et al., 2009).

- Cognitive load reduction - reducing information overload in contexts with a large number of contexts that required attention from decision makers becomes important (Druckenmiller, 2009; Fan, McNeese, \& Yen, 2010).

- Transparency and accessibility of evidence - capturing evidence of the various perspectives or positions outlined above and making this clearly and freely available to all stakeholders (Biermann, 2011; Renton \& Macintosh, 2007; Ritchey, 2006).

- User interface and visual feedback - the process of working through the decision process should be presented in a user-friendly manner that provides clear visual representations of the problem situation and activities undertaken (Balram \& Dragicevic, 2006; Biermann, 2011; Coorey \& Jupp, 2014; Druckenmiller, 2009; Giordano et al., 2007; Jankowski et al., 1997; Jankowski \& Nyerges, 2001; Jarupathirun \& Zahedi, 2007; Kulinich, 2012; Mackenzie et al., 2006; Marashi 
\& Davis, 2007; McIntosh et al., 2011; Munneke et al., 2007; Renton \& Macintosh, 2007; Ritchey, 2006; Van Delden, Seppelt, White, \& Jakeman, 2011; Van Kouwen et al., 2009).

- Facilitation of organizational memory - issues addressed in the past should be stored effectively such that recall and application to novel and familiar contexts is supported (Conklin \& Begeman, 1989; Chen \& Lee, 2003; El-Gayar \& Fritz, 2010; Renton \& Macintosh, 2007).

- Flexibility of phases and iterations - the processing of resolving a wicked problem is not linear, therefore, the process explored by the DSS should allow for iterative deliberation to reach consensus the process of wicked problem exploration and capturing of information should not be a once-off, sequential process, but may require many iterations to create a cohesive picture as well as to reach consensus (Applegate, Chen, Konsynski, \& Nunamaker, 1987; Cil et al., 2005; Kulinich, 2012).

- Reduction of erroneous logic - despite the freedom necessary in wicked problem exploration, there should also exist tools to locate cognitive biases and other oversights and inconsistencies in the deliberation process (Chen \& Lee, 2003; Karacapilidis, 2000; Karacapilidis \& Papadias, 2001).

- Decision analysis methods - a number of studies still support the use of mathematical models to assist with calculations and provision of information (Cil et al., 2005; Giupponi, 2007; Goslar, 1986; Gu \& Tang, 2005; Jankowski et al., 1997; Jankowski \& Nyerges, 2001).

These findings are fairly consistent with arguments made by other authors for wicked problem resolution. Further, a number of these features also correspond with the procedural approach to decision support discussed in the background section. This demonstrates that procedural decision support, which was theoretically argued by authors such as H. A. Simon (1976) and Mackenzie et al. (2006) to be superior for wicked problem resolution, is supported by the literature gathered.

\subsection{A Procedural DSS for Wicked Problems}

The findings from the previous sections demonstrate the preference in the literature for procedural decision support over substantive or even mixed approaches. To this end and in light of the arguments presented prior to the study, a conceptual model for the design, development, and use of a DSS for resolving wicked problems is presented in order to address the final research question. To synthesize this model, the 23 articles specifically considering procedural decision support in the literature were analyzed for common themes and patterns regarding the architecture of such a DSS, as well as the soft factors that were identified. A graphical representation of the model is presented in Figure 5. 


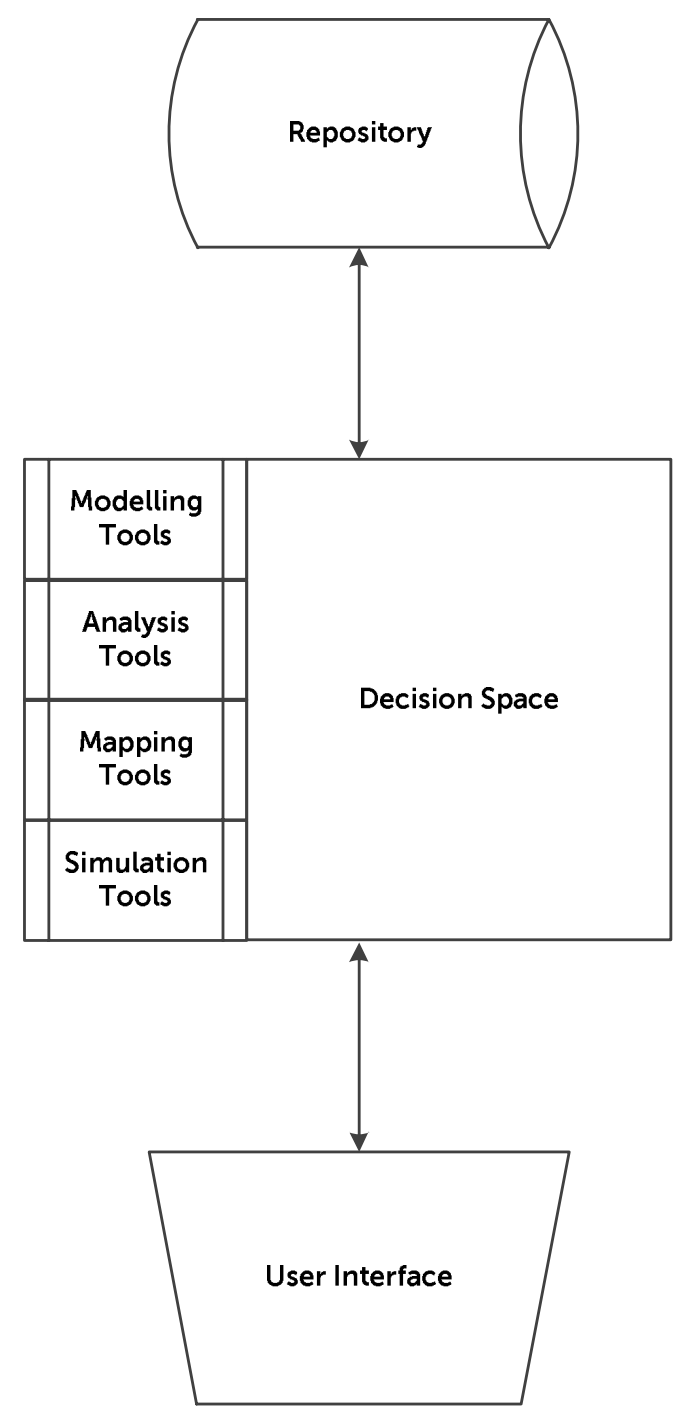

Figure 5: Synthesised conceptual model of procedural DSSs 


\subsubsection{Architecture}

The components of a procedural DSS are as follows:

- Repository - the creation and facilitation of organizational memory was a requirement for procedural DSS noted by a number of studies. A repository fulfills this function by storing previous deliberations, scenarios, and outcomes. This permits revisitation of previous scenarios, informing concerns around novel or recurring wicked problems.

- Decision space - functions as a virtual whiteboard, where multiple perspectives and facts regarding the problem can be captured and discussed. This allows the decision context to be navigated individually or collectively, facilitating sensemaking. The movement between ideas, perspectives, and plausible strategies is not necessarily enforced in a linear fashion as the process order is subject to negotiation via use of various tools embedded within this space.

- Decision tools - utilized in order to explore, analyze, and simulate various aspects of the wicked problem within the decision space. Mapping and modeling tools facilitate exploration of the problem situation in a linguistic, semantic, and visual manner. Simulation can predict the effects of alternatives, and analysis tools can assist with evaluation of alternatives in terms of preferences captured in the decision space.

- User interface - imperative to allow interaction between stakeholders and the system. Also facilitates varying levels of analysis at which perception and manipulation of the decision space can occur.

\subsubsection{DSS Design and Development Process}

It is argued that the traditional systems development life cycle (SDLC) approach to software development is overly deterministic for wicked problems, presupposing the existence of definitive system goals (Klashner \& Sabet, 2007). Authors such as Klashner and Sabet (2007) argue that an evolutionary spiral model or an evolutionary DSS model (Arnott, 2004) is more appropriate. The plausible irony that the possibility of design and development of a procedural DSS for wicked problems may itself constitute a wicked problem is not always explicitly acknowledged in the literature, but is implicitly recognized in a number of sources. Either way, it becomes imperative to refine the DSS design as new information is discovered.

In addition to an evolutionary model of DSS design and development, it is argued that stakeholder involvement is imperative in light of the required featured uncovered in the qualitative analysis.

\subsubsection{Decision Process}

The widely accepted view of the decision making process developed by H. Simon (1960) comprises three discrete phases: intelligence, design, and choice. Later models added decision implementation and review phases. Although the phase model was originally intended to be recursive, allowing iterative movement through the phases (Arnott \& Pervan, 2014), it is often treated as a sequential process very much like the SDLC. However, it seems insensible to force non-deterministic wicked 


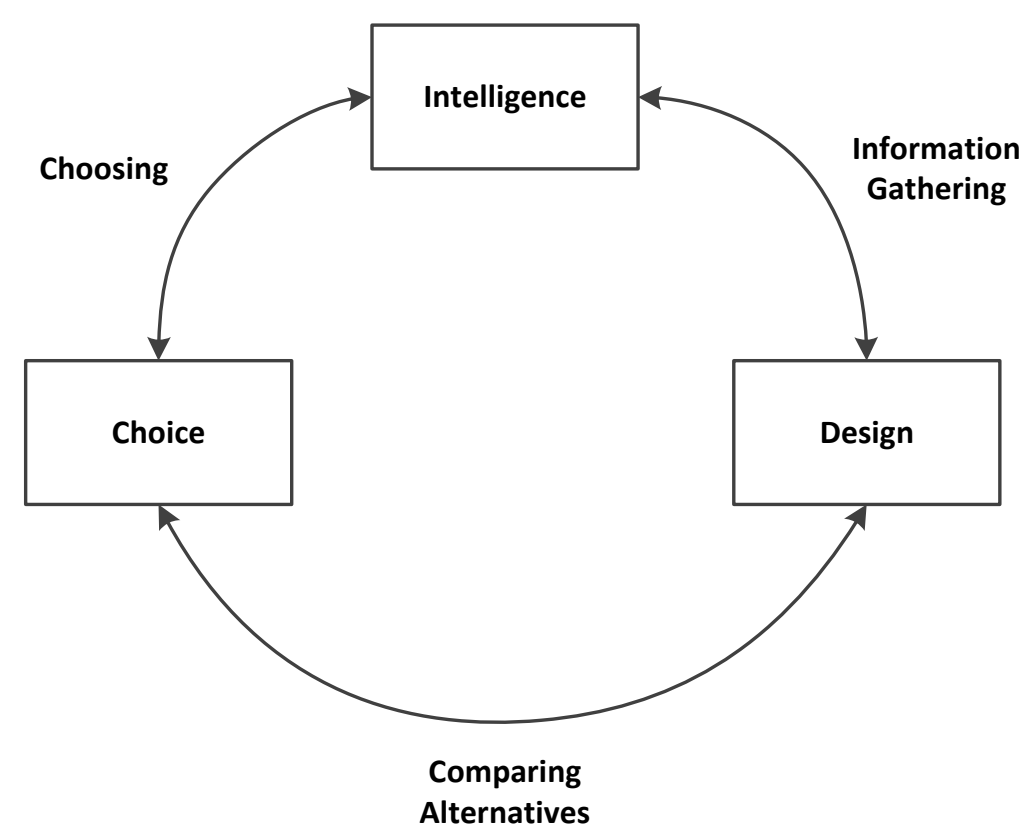

Figure 6: Decision making process as described by (H. Simon, 1960)

problems to fit a sequential process of deliberation. Therefore, the procedural DSS deliberation process is cyclical as well as evolutionary, allowing stakeholders to capture perspectives, explore, analyze, simulate, and evaluate iteratively. This process is demonstrated in Figure 6.

\subsubsection{Organizational Perspective}

A number of other authors argue that organizations facing wicked problems should adopt a Singerian perspective within the organization, emphasizing the inquiring character that should be adopted (Courtney, 2001). Fundamentally, a Singerian organization views reality holistically, and as a system that is highly interconnected and indivisible in nature. Pragmatically, problem solving is undertaken in a comprehensive and unified manner, with the view of wicked problems as integrated wholes. Another important point related to the Singerian view is closely embedded in the subjective nature of wicked problems. Mitroff and Linstone summarise this as follows:

All complex problems - especially social ones — involve a multiplicity of actors, various scientific/technical disciplines, and various organizations and diverse individuals. In principle, each sees a problem differently and thus generates a distinct perspective on it. (1993, p. 99)

Consequently, an inquiring, Singerian, organizational context that effectively implements the procedural DSS will not simply embrace the technical elements of the wicked problem, but also the personal, organizational, and ethical perspectives. This corresponds with the requirements for procedural decision support presented in the literature. 
Pragmatically, a Singerian organization is teleological, in the sense that it always works towards a common goal, the overarching goal being the creation of exoteric knowledge ${ }^{2}$ (Richardson, Courtney, \& Haynes, 2006). This means that such an organization will attempt to create knowledge that is applicable to a wide range of domains rather than merely looking to solve a particular occurrence of a problem. Additionally, this process of knowledge creation relies on individuals within the organization to behave cooperatively, ethically, and critically in order to facilitate the process of overcoming disagreement through socialization and externalization ${ }^{3}$ of knowledge (Courtney, 2001). This means that such an organization must strive to create an environment where trust between stakeholders can be nurtured. Finally, the organization must be comfortable with the notion of sweeping in change, or adapting requirements as more knowledge from the outside becomes available (Richardson et al., 2006). Therefore, an organization that adopts a Singerian view should be open to engaging in dialogue about a wicked problem, be willing to accommodation multiple, often conflicting perspectives, and be adaptive to the shifting nature of wicked problems (Richardson et al., 2006).

\section{CONCLUSION}

The overarching objective of this article was to investigate the advantages of procedural decision support over substantive decision support, to explore the prevalence of each in the literature, as well as to investigate the nature of procedural decision support. Consequently, five research questions were synthesized as presented in the introductory section; these were answered in the previous sections.

A three-phase research design was implemented in order to answer these questions. Firstly, key themes in decision making, wicked problems, and DSSs literature as reference disciplines were consulted. This analysis built the case for shortcomings inherent in human reasoning, the immense difficulty of wicked problem contexts, and the possibility of supporting these problems through a procedural DSS. Secondly, a quantitative and qualitative analysis of the systematically sampled literature regarding DSSs in wicked contexts was performed. The desirable features of procedural DSSs as well as the cognizance of such systems in the literature were elucidated. Finally, these perspectives were integrated to form a cohesive model for procedural decision support, including architectural, organizational, and pragmatic themes.

\subsection{Limitations of Research}

The fact that an interpretive, theoretical research design was implemented may have a number of limitations. Non-empirical research mean secondary sources, and these can plausibly produce less

\footnotetext{
${ }^{2}$ Here, exoteric knowledge refers to knowledge that is useful for a variety of individuals in different contexts, organizations, and societies rather than being applicable to a narrow domain such as those dictated by highly scientific knowledge.

${ }^{3}$ Nonaka (1994)'s conception of knowledge creation refers to socialization as the creation of tacit knowledge through shared experience, and externalization as the process of converting tacit knowledge to explicit knowledge.
} 
reliable results than primary data sources. However, as the objective of the research is to contribute to the theoretical landscape of DSSs for wicked problems, this study serves as a preliminary step in the greater intellectual process of defining this field. A second possible limitation of the design refers to the literature sampling strategy. As the sample only included those studies that explicitly noted wickedness, there is a real risk that a significant scope of actual wicked problem contexts were excluded. Therefore, findings are only applicable to situations where there is cognizance of the wickedness of the problem being studied.

\subsection{Future Work}

A number of opportunities for future work exist. Firstly, a larger sample of literature could be selected via a test for wickedness as opposed to explicit awareness and explication of this wickedness on the part of the authors. This would presumably yield a larger literature sample than this study uncovered. Secondly, the findings of this research could be supplemented by undertaking empirical work such as a wicked problem case study, where the model is applied conceptually. Finally, a design science endeavor could be utilized to address questions around usability or suitability of the modelled procedural DSS for resolving wicked problems, by actually building the modelled artifact, and testing it in a particular context or groups of related contexts. This could be further extended to cover dissimilar problem contexts to control for problem similarity in determining the artifact's suitability for addressing wicked problems.

\section{ACKNOWLEDGEMENTS}

The financial assistance of the Harry Crossley Foundation towards this research is hereby acknowledged.

\section{References}

Allais, M. (1979). The so-called Allais paradox and rational decisions under uncertainty. In M. Allais \& O. Hagen (Eds.), Expected utility hypotheses and the Allais paradox (pp. 437-654). Springer. https://doi.org/10.1007/978-94-015-7629-1_17

Alter, S. (1977). A taxonomy of decision support systems. Sloan Management Review, 19(1), 39-56. Anthony, R. (1965). Planning and control systems: A framework for analysis. Studies in Management Control. Division of Research, Graduate School of Business Administration, Harvard University. Applegate, L. M., Chen, T. T., Konsynski, B. R., \& Nunamaker, J. F. J. (1987). Knowledge management in organizational planning. Journal of Management Information Systems, 3(4), 20-38. https: //doi.org/10.1080/07421222.1987.11517776

Arnott, D. (2004). Decision support systems evolution: Framework, case study and research agenda. European Journal of Information Systems, 13(4), 247-259. https:// doi.org/10.1057/ palgrave.ejis.3000509 
Arnott, D. (2006). Cognitive biases and decision support systems development: A design science approach. Information Systems Journal, 16(1), 55-78. https://doi.org/10.1111/j.13652575.2006.00208.x

Arnott, D. \& Pervan, G. (2005). A critical analysis of decision support systems research. Journal of Information Technology, 20(2), 67-87. https://doi.org/10.1057/palgrave.jit.2000035

Arnott, D. \& Pervan, G. (2008). Eight key issues for the decision support systems discipline. Decision Support Systems, 44(3), 657-672. https://doi.org/10.1016/j.dss.2007.09.003

Arnott, D. \& Pervan, G. (2014). A critical analysis of decision support systems research revisited: The rise of design science. Journal of Information Technology, 29(4), 269-293. https://doi.org/10. 1057/jit.2014.16

Avison, D. \& Fitzgerald, G. (2002). Information systems development: Methodologies, techniques \& tools (4th). McGraw-Hill Education.

Babbie, E. \& Mouton, J. (2007). The practice of social research (7th ed.). Oxford University Press Southern Africa (Pty) Ltd.

Balram, S. \& Dragicevic, S. (2006). Modeling collaborative GIS processes using soft systems theory, UML and object oriented design. Transactions in GIS, 10(2), 199-218. https://doi.org/10. 1111/j.1467-9671.2006.00253.x

Bernstein, P. L. (1996). Against the gods. John Wiley \& Sons.

Biermann, S. (2011). Planning support systems in a multi-dualistic spatial planning context. Journal of Urban Technology, 18(4), 5-37. https://doi.org/10.1080/10630732.2011.648432

Blackman, T., Elliot, E., Greene, A., Harrington, B., Hunter, D. J., Marks, L., ... Williams, G. (2006). Performance assessment and wicked problems: The case of health inequalities. Public Policy and Administration, 21(2), 66-80.

Bonczek, R., Holsapple, C., \& Whinston, A. (1981). Foundations of decision support systems. Academic Press.

Brooks, J. J. \& Champ, P. A. (2006). Understanding the wicked nature of "unmanaged recreation" in Colorado's Front Range. Environmental Management, 38(5), 784-798. https://doi.org/10. 1007/s00267-005-0372-2

Buchanan, L. \& O' Connell, A. (2006). A brief history of decision making. Harvard Business Review, 84(1), 32-41.

Buchanan, R. (1992). Wicked problems in design thinking. Design Issues, 8(2), 5-21.

Burstein, F. \& Holsapple, C. W. (2008). Preface. In F. Burstein \& C. W. Holsapple (Eds.), Handbook on decision support systems (pp. VII-XX). Springer-Verlag. https://doi.org/10.1007/978-3540-48713-5

Camillus, J. C. (2008). Strategy as a wicked problem. Harvard Business Review, 86(5), 98-106.

Carabelli, A. (2002). Speculation and reasonableness: a non-bayesian theory of rationality. In S. C. Dow \& J. Hillard (Eds.), Keynes, uncertainty and the global economy (pp. 165-185). Edward Elgar. https://doi.org/10.4337/9781781950050.00017

Chen, J. Q. \& Lee, S. M. (2003). An exploratory cognitive dss for strategic decision making. Decision Support Systems, 36(4), 147-160. https://doi.org/10.1016/S0167-9236(02)00139-2 
Churchman, C. W. (1967). Guest editorial: Wicked problems. Management Science, 14(4), B141-B142. https://doi.org/10.1097/NAQ.0000000000000063

Cil, I., Alpturk, O., \& Yazgan, H. R. (2005). A new collaborative system framework based on a multiple perspective approach: InteliTeam. Decision Support Systems, 39(4), 619-641. https: //doi.org/10.1016/j.dss.2004.03.007

Conklin, J. (2005). Wicked problems and social complexity. In Dialogue mapping: Building shared understanding of wicked problems (Chap. 1). Chichester: John Wiley \& Sons.

Conklin, J. \& Begeman, M. L. (1989). gIBIS: A tool for all reasons. Journal of the American Society for Information Science, 40(3), 200-213. https://doi.org/10.1002/(SICI)1097-4571(198905) 40:3<200::AID-ASI11>3.0.C0;2-U

Coorey, B. P. \& Jupp, J. R. (2014). Generative spatial performance design system. Artificial Intelligence for Engineering Design, Analysis and Manufacturing, 28(3), 277-283. https://doi.org/10. $1017 /$ S0890060414000225

Courtney, J. F. (2001). Decision making and knowledge management in inquiring organizations: Toward a new decision-making paradigm for DSS. Decision Support Systems, 31(1), 17-38. https://doi.org/10.1016/S0167-9236(00)00117-2

Druckenmiller, D. A. (2009). An agent-based collaborative approach to graphing causal maps for situation formulation. Journal of the Association for Information Systems, 10 (3), 221-251.

Durant, R. F. \& Legge, J. S. (2006). "Wicked problems," public policy, and administrative theory: Lessons from the GM food regulatory arena. Administration \& Society, 38(3), 309-334. https: //doi.org/10.1177/0095399706289713

EBSCO Industries Inc. (2015). EBSCOhost. Retrieved from https://www.ebscohost.com

Ellsberg, D. (1961). Risk, ambiguity, and the savage axioms. The Quarterly Journal of Economics, 75(4), 643-669. https://doi.org/10.2307/1884324

Evans, J. S. B. T. (1984). Heuristic and analytic processes in reasoning. British Journal of Psychology, 75(4), 451-468. https://doi.org/10.1111/j.2044-8295.1984.tb01915.x

Fan, X., McNeese, M., \& Yen, J. (2010). NDM-based cognitive agents for supporting decisionmaking teams. Human-Computer Interaction, 25(3), 195-234. https://doi.org/10.1080/ 07370020903586720

Freeman, D. M. (2000). Wicked water problems: Sociology and local water organizations in addressing water resources policy. Journal of the American Water Resources Association, 36(3), 483-491.

Friedman, M. \& Savage, L. (1952). The expected-utility hypothesis and the measurability of utility. The Journal of Political Economy, 60(6), 463-474. https://doi.org/10.1086/257308

El-Gayar, O. F. \& Fritz, B. D. (2010). A web-based multi-perspective decision support system for information security planning. Decision Support Systems, 50(1), 43-54. https://doi.org/10. 1016/j.dss.2010.07.001

Gigerenzer, G. (2004). Fast and frugal heuristics: The tools of bounded rationality. In D. J. Koehler \& N. Harvey (Eds.), Blackwell handbook of judgment and decision making (Chap. 4, pp. 62-88). Blackwell Publishing. https://doi.org/10.1002/9780470752937.ch4 
Gigerenzer, G. \& Gaissmaier, W. (2011). Heuristic decision making. Annual Review of Psychology, 62, 451-482. https://doi.org/10.1146/annurev-psych-120709-145346

Giordano, R., Passarella, G., Uricchio, V. F., \& Vurro, M. (2007). Integrating conflict analysis and consensus reaching in a decision support system for water resource management. Journal of Environmental Management, 84(2), 213-228. https://doi.org/10.1016/j.jenvman.2006.05. 006

Giupponi, C. (2007). Decision support systems for implementing the European Water Framework Directive: The MULINO approach. Environmental Modelling \& Software, 22(2), 248-258. https: //doi.org/10.1016/j.envsoft.2005.07.024

Gorry, G. A. \& Morton, M. S. S. (1989). A framework for management information systems. Sloan Management Review, 30(3), 49-61.

Goslar, M. D. (1986). Capability criteria for marketing decision support systems. Journal of Management Information Systems, 3(1), 81-95. https:// doi.org/10.1080/07421222.1986. 11517756

Gu, J. \& Tang, X. (2005). Meta-synthesis approach to complex system modeling. European Journal of Operational Research, 166(3), 597-614. https://doi.org/10.1016/j.ejor.2004.03.036

Hackathorn, R. D. \& Keen, P. G. W. (1981). Organizational strategies for personal computing in decision support systems. MIS Quarterly, 5(3), 21. https://doi.org/10.2307/249288

Hacking, I. (1972). The logic of pascal's wager. American Philosophical Quarterly, 9(2), 186-192. https://doi.org/10.2307/20009437

Hansson, S. O. (2002). Preference logic. In D. M. Gabbay \& F. Guenthner (Eds.), Handbook of philosophical logic (2nd ed., Chap. 4, pp. 319-393). Springer. https://doi.org/10.1007/97894-017-0456-4_4

Hayen, R. L. (2006). Investigating decision support systems frameworks. Issues in Information Systems, 7(2), 9-13.

Holsapple, C. (2008). DSS architecture and types. In F. Burstein \& C. W. Holsapple (Eds.), Handbook on decision support systems 1 (Chap. 9, pp. 163-189). Springer-Verlag. https://doi.org/10. 1007/978-3-540-48713-5_9

Jankowski, P. \& Nyerges, T. (2001). GIS-supported collaborative decision making: Results of an experiment. Annals of the Association of American Geographers, 91 (1), 48-70. https://doi.org/ 10.1111/0004-5608.00233

Jankowski, P., Nyerges, T. L., Smith, A., Moore, T. J., \& Horvath, E. (1997). Spatial group choice: A SDSS tool for collaborative spatial decisionmaking. International Journal of Geographical Information Science, 11(6), 577-602. https://doi.org/10.1080/136588197242202

Jarupathirun, S. \& Zahedi, F. (2007). Dialectic decision support systems: System design and empirical evaluation. Decision Support Systems, 43(4), 1553-1570. https://doi.org/10.1016/j.dss. 2006.03.002

Jarvenpaa, S. L., Rao, V. S., \& Huber, G. P. (1988). Computer support for meetings of groups working on unstructured problems: A field experiment. MIS Quarterly, 12(4), 645-666. https://doi. org/10.2307/249137 
Jentoft, S. \& Chuenpagdee, R. (2009). Fisheries and coastal governance as a wicked problem. Marine Policy, 33(4), 553-560. https://doi.org/10.1016/j.marpol.2008.12.002

Kahneman, D. (2011). Thinking, fast and slow. UK: Penguin.

Kahneman, D. \& Tversky, A. (1979). Prospect theory: An analysis of decision under risk. Econometrica, 47(2), 263-292. https://doi.org/10.2307/1914185

Karacapilidis, N. (2000). Integrating new information and communication technologies in a group decision support system. International Transactions in Operational Research, 7(6), 487. DOI: 10.1016/S0969-6016(00)00028-9

Karacapilidis, N. \& Papadias, D. (2001). Computer supported argumentation and collaborative decision making: The HERMES system. Information Systems, 26(4), 259-277. https://doi. org/10.1016/S0306-4379(01)00020-5

Keen, P. G. W. (1980). Decision support systems: A research perspective. In G. Fick \& R. H. Sprague (Eds.), Decision support systems issues and challenges: Proceedings of an international task force meeting (pp. 23-44). Pergamon Press.

Keen, P. G. W. \& Morton, S. S. (1978). Decision support systems: An organisational perspective. AddisonWesley.

Keren, G. \& Teigen, K. H. (2004). Yet another look at the heuristics and biases approach. In D. J. Koehler \& N. Harvey (Eds.), Blackwell handbook of judgment and decision making (Chap. 5, pp. 89-109). Blackwell Publishing. https://doi.org/10.1002/9780470752937.ch5

Klashner, R. \& Sabet, S. (2007). A DSS design model for complex problems: Lessons from mission critical infrastructure. Decision Support Systems, 43(3), 990-1013. https://doi.org/10.1016/ j.dss.2005.05.027

Klein, G. (2008). Naturalistic decision making. Human Factors, 50(3), 456-460. https://doi.org/10. 1518/001872008X288385.. arXiv: arXiv:1011.1669v3

Klein, G. (2015). Reflections on applications of naturalistic decision making. Journal of Occupational and Organizational Psychology, 88(2), 382-386. https://doi.org/10.1111/joop.12122

Korac-Kakabadse, N., Kouzmin, A., \& Korac-Kakabadse, A. (2000). Information technology and development: Creating 'IT Harems', fostering new colonialism or solving 'wicked' policy problems? Public Administration and Development, 20(3), 171-184.

Kreuter, M. W., De Rosa, C., Howze, E. H., \& Baldwin, G. T. (2004). Understanding wicked problems: A key to advancing environmental health promotion. Health Education \& Behavior, 31 (4), 441-454. https://doi.org/10.1177/1090198104265597

Kulinich, A. A. (2012). Computer systems for cognitive maps simulation: Approaches and methods. Automation and Remote Control, 73(10), 1715-1733. https:// doi.org/10.1134/ S0005117912100116

Kunz, W. \& Rittel, H. W. (1970). Issues as elements of information systems. Institute of Urban and Regional Development, University of California Berkeley, California.

Laville, F. (2000). Foundations of procedural rationality: Cognitive limits and decision processes. Economics and Philosophy, 16(1), 117-138. https://doi.org/10.1017/S026626710000016X

Lazarus, R. J. (2009). Super wicked problems and climate change: Restraining the present to liberate the future. Cornell Law Review, 94(5), 1153-1234. 
Levy, Y. \& Ellis, T. (2006). A systems approach to conduct an effective literature review in support of information systems research. Informing Science Journal, 9(1), 181-212.

Lipshitz, R., Klein, G., Orasanu, J., \& Salas, E. (2001). Focus article: Taking stock of naturalistic decision making. Journal of Behavioral Decision Making, 14(5), 331-352. https://doi.org/10. 1002/bdm.381

Lourenço, R. P. \& Costa, J. P. (2007). Incorporating citizens' views in local policy decision making processes. Decision Support Systems, 43(4), 1499-1511. https://doi.org/10.1016/j.dss. 2006.06.004

Mackenzie, A., Pidd, M., Rooksby, J., Sommerville, I., Warren, I., \& Westcombe, M. (2006). Wisdom, decision support and paradigms of decision making. European Journal of Operational Research, 170(1), 156-171. https://doi.org/10.1016/j.ejor.2004.07.041

Marashi, E. \& Davis, J. P. (2007). A systems-based approach for supporting discourse in decision making. Computer-Aided Civil and Infrastructure Engineering, 22(7), 511-526. https://doi. org/10.1111/j.1467-8667.2007.00507.x

March, J. G. (1994). A primer on decision making. Free Press.

McIntosh, B. S., Ascough, J. C., Twery, M., Chew, J., Elmahdi, A., Haase, D., ... Voinov, A. (2011). Environmental Decision Support Systems (EDSS) development-Challenges and best practices. Environmental Modelling and Software, 26(12), 1389-1402. https://doi.org/10.1016/j. envsoft.2011.09.009

Mitroff, I. I. \& Linstone, H. A. (1993). The unbounded mind: Breaking the chains of traditional business thinking. Oxford University Press.

Mongin, P. (1997). Expected utility theory. In J. Davis, W. Hands, \& U. Maki (Eds.), Handbook of economic methodology (pp. 342-350). Edward Elgar.

Munneke, L., Andriessen, J., Kanselaar, G., \& Kirschner, P. (2007). Supporting interactive argumentation: Influence of representational tools on discussing a wicked problem. Computers in Human Behavior, 23(3), https://doi.org/10.2-1088. https://doi.org/10.1016/j.chb.2006.10.003

Nonaka, I. (1994, February). A dynamic theory of organizational knowledge creation. Organization Science, 5(1), 14-37. https://doi.org/10.1287/orsc.5.1.14

O’Toole, L. J. (1997). Treating networks seriously: Practical and research-based agendas in public administration. Public Administration Review, 57(1), 45-52.

Over, D. (2004). Rationality and the normative / descriptive distinction. In D. J. Koehler \& N. Harvey (Eds.), Blackwell handbook of judgment and decision making (Chap. 1, pp. 3-18). Blackwell Publishing. https://doi.org/10.1002/9780470752937.ch1

Pearson, J. \& Shim, J. (1995). An empirical investigation into dss structures and environments. Decision Support Systems, 13(2), 141-158. https://doi.org/10.1016/0167-9236(93)E0042$\mathrm{C}$

Peterson, M. (2009). An introduction to decision theory. Cambridge University Press.

Pidd, M. (2004). Contemporary OR/MS in strategy development and policy making: Some reflections. Journal of Operational Research Society, 55(8), 791-800. https://doi.org/10.1057/palgrave. jors. 2601748 
Power, D. J. (2001). Supporting decision-makers: An expanded framework. In Informing Science (Vol. 1, June, pp. 1901-1915). https://doi.org/10.1109/JSAC.2006.877218

Power, D. J. (2002). Decision support systems: Concepts and resources for managers. Greenwood Publishing Group.

Power, D. J. (2008). Decision support systems: A historical overview. In F. Burstein \& C. W. Holsapple (Eds.), Handbook on decision support systems (Chap. 7, pp. 121-140). Springer-Verlag. https: //doi.org/10.1007/978-3-540-48713-5

Pretorius, C. (2016). Supporting wicked problems with procedural decision support systems. In Proceedings of the Annual Conference of the South African Institute of Computer Scientists and Information Technologists (p. 33). ACM. 10.1145/2987491.2987515

Renton, A. \& Macintosh, A. (2007). Computer-supported argument maps as a policy memory. Information Society, 23(2), 125-133. https://doi.org/10.1080/01972240701209300

Richardson, S. M., Courtney, J. F., \& Haynes, J. D. (2006). Theoretical principles for knowledge management system design: Application to pediatric bipolar disorder. Decision Support Systems, 42(3), 1321-1337. https://doi.org/10.1016/j.dss.2005.11.001

Ritchey, T. (2006). Problem structuring using computer-aided morphological analysis. Journal of the Operational Research Society, 57(7), 792-801. https://doi.org/10.1057/palgrave.jors. 2602177

Ritchey, T. (2011). Wicked problems—social messes: Decision support modelling with morphological analysis. Springer-Verlag. https://doi.org/10.1007/978-3-642-19653-9

Ritchey, T. (2013). Wicked problems: Modelling social messes with morphological analysis. Acta Morphologica Generalis, 2(1), 1-8.

Rittel, H. W. J. \& Webber, M. M. (1973). Dilemmas in a general theory of planning. Policy Sciences, 4(2), 155-169. https://doi.org/10.1007/BF01405730

Roberts, N. (2000). Wicked problems and network approaches to resolution. International Public Management Review, 1(1), 1-19.

Shim, J., Warkentin, M., Courtney, J. F., Power, D. J., Sharda, R., \& Carlsson, C. (2002). Past, present, and future of decision support technology. Decision Support Systems, 33(2), 111-126. https://doi.org/10.1016/S0167-9236(01)00139-7

Simon, H. (1960). The new science of management decision. Prentice-Hall.

Simon, H. A. (1955). A behavioral model of rational choice. The Quarterly Journal of Economics, 69(1), 99-118. https://doi.org/10.2307/1884852

Simon, H. A. (1956). Rational choice and the structure of the environment. Psychological Review, 63(2), 129-138. https://doi.org/10.1037/h0042769

Simon, H. A. (1976). From substantive to procedural rationality. In T. J. Kastelein, S. K. Kuipers, W. A. Nijenhuis, \& G. R. Wagenaar (Eds.), 25 years of economic theory: Retrospect and prospect (pp. 65-86). Springer. https://doi.org/10.1007/978-1-4613-4367-7\{\\}6

Simon, H. A. (1979). Rational decision making in business organizations. The American Economic Review, 69(4), 493-513. https://doi.org/10.2307/1808698

Skaburskis, A. (2008). The origin of "wicked problems". Planning Theory \& Practice, 9(2), 277-280. https://doi.org/10.1080/14649350802041654 
Sprague, R. H. (1980). A framework for the development of decision support systems. MIS Quarterly, 4(4), 1-26. https://doi.org/10.2307/248957

Sprague, R. H. (1987). DSS in context. Decision Support Systems, 3(3), 197-202. https://doi.org/ 10.1016/0167-9236(87)90174-6

Stanovich, K. E. \& West, R. F. (2000). Individual differences in reasoning: Implications for the rationality debate? The Behavioral and Brain Sciences, 23(5), 645-726. https://doi.org/10. 1017/S0140525X00003435. arXiv: 0402594v3 [arXiv:cond-mat]

Swinburn, B. A., Sacks, G., Hall, K. D., McPherson, K., Finegood, D. T., Moodie, M. L., \& Gortmaker, S. L. (2011). The global obesity pandemic: Shaped by global drivers and local environments. Lancet, 378(9793), 804-814. https://doi.org/10.1016/S0140-6736(11)60813-1

Thomson Reuters. (2015). Web of science.

Tversky, A. \& Kahneman, D. (1974). Judgment under uncertainty: Heuristics and biases. Science, 185(4157), 1124-1131. https://doi.org/10.1126/science.185.4157.1124

Tversky, A. \& Kahneman, D. (1981). The framing of decisions and the psychology of choice. Science, 211(4481), 453-458. https://doi.org/10.1126/science.7455683

Tversky, A. \& Kahneman, D. (1986). Rational choice and the framing of decisions. Journal of Business, 59(4), S251-S278. https://doi.org/10.2307/2352759

Van Delden, H., Seppelt, R., White, R., \& Jakeman, A. (2011). A methodology for the design and development of integrated models for policy support. Environmental Modelling \& Software, 26(3), 266-279. https://doi.org/10.1016/j.envsoft.2010.03.021

Van Kouwen, F., Dieperink, C., Schot, P., \& Wassen, M. (2009). Computer-supported cognitive mapping for participatory problem structuring. Environment and Planning, 41(1), 63-81. https://doi.org/10.1068/a4099

Webster, J. \& Watson, R. (2002). Analyzing the past to prepare for the future: Writing a literature review. Management Information Systems Quarterly, 26(2), xiii-xxiii. https://doi.org/10. $2307 / 4132319$ 